\title{
LETTERS
}

\section{Deromanticizing medical assistance in dying}

In response to Dr. Ashe's article on providing his 100th case of medical assistance in dying (MAiD), ${ }^{1}$ we wish to counter with our concerns about his romantic view of MAiD and its potential impact, his underestimation of the frequency of MAiD and his assertion that MAiD is an act of mercy and respect.

Dr. Ashe speaks of providing MAiD as an "intimate and sacred moment." We trust that he meant the interaction with the suffering patient and family before administration of the medications to end a life. Rocuronium, which paralyzes the neuromuscular junction and terminates life, does not allow for any expression of what the patient is feeling. We do not believe it is in the best interest of others to portray MAiD as something people should seek instead of natural death, for 2 reasons.

First, other nations have had MAiD for some time now, and we should look to them to see our possible future. A recent survey of physicians in the Netherlands ${ }^{2}$ reported that many had contradictory feelings of satisfaction and burden after performing euthanasia, that ambiguity about being involved in requests for and performing euthanasia has increased over the past 20 years and that physicians are feeling increasingly pressured to perform this service by patients and family members who now see it as normal practice and their right.

Second, writing about MAiD in a romanticized way may influence vulnerable people to seek MAiD through social learning, whereby they identify with the person portrayed and seek to copy their behaviour. This has been previously reported in 2003 in Switzerland. ${ }^{3}$

Dr. Ashe implied he was led to support MAiD after experiences with patients who died by suicide when they had a serious illness. We are sure his thinking was more complex, but he suggests that he questioned whether there could be a "better way." In so doing, he was not reviewing how depression and hopelessness from suffering could be better assessed and ameliorated, but how someone could hasten their death without traumatizing others. We would not have the medical advances and healthier, longer lives we have today if previous clinicians all considered an easier death to be the solution to the burden of disease. We need to continue to research and seek ways of preventing and relieving suffering.

Responses to Dr. Ashe's article have pointed out that palliative care is distinct from MAiD, yet this ongoing conflation is common. We believe those who seek to combine MAiD with palliative care seek to make it an option for end-of-life rather than an exception as intended by the law. According to Health Canada, in 2019, MAiD already accounted for $2 \%$ of deaths in our country, ${ }^{4}$ and this is prior to opening the criteria to those whose deaths are not reasonably foreseeable and to those with mental illness. Euthanasia is reported as $4.2 \%$ of all deaths (possibly as much as $20 \%$ higher, as reporting is not mandatory) in the Netherlands in 2019. ${ }^{5}$

Dr. Ashe concludes his article by stating that MAiD should be seen "as the act of mercy and respect that it truly is." We respectfully do not share his opinion. Many other voices are also being raised in opposition, particularly to the expansion of MAiD. On Feb. 23, 2021, the Canadian Mental Health Association released a statement indicated that it is "deeply disappointed that the government supports allowing those with mental illnesses to seek medical assistance in dying. ${ }^{16} \mathrm{~A}$ policy statement from the Canadian Centre for Addiction and Mental Health recommended against allowing MAiD for mental illness alone. ${ }^{7}$ More than 300 disability advocacy groups in Canada have voiced opposition to the Bill C-7 amendments rushed through the legislative process by the Liberal government. ${ }^{8}$ The United Nations Human Rights Council's special rapporteur on the rights of persons with disabilities has also voiced concerns about Bill C-7. ${ }^{9}$ Professional groups, such as the World Medical Association, ${ }^{10}$ the British Medical Association, ${ }^{11}$ the American Medical Association ${ }^{12,13}$ and the American Psychiatric Association ${ }^{14}$ have all expressed unwavering opposition to MAiD.
Data from Ontario have shown that MAiD is primarily sought by privileged, wealthy and educated Canadians. ${ }^{15}$ Now that MAiD has been expanded to include nonterminal conditions and, eventually, mental illness as sole criterion, the applicant demographic will likely begin shifting to include those from disadvantaged backgrounds with limited access to quality palliative care, disability support or mental health services. We are concerned that the enhanced freedom to choose MAiD will come at the expense of their vulnerable and disadvantaged compatriots, having been granted the "take it or leave it" choice of MAiD versus suffering within a health system that has failed to adequately serve them.

Our opinion is that equitable access to quality palliative care, disability support and mental health care would better reflect the mercy and respect that all Canadians truly deserve.

\section{Romayne Gallagher MD}

Palliative care physician (retired), Providence Health Care, Vancouver, BC

\section{Michael J. Passmore MD}

Psychiatrist, Providence Health Care, Vancouver, BC

- Cite as: CMAJ 2021 July 5;193:E1012-3. doi: $10.1503 / \mathrm{cmaj} .78845$

\section{References}

1. Ashe GP. A unique milestone. CMAJ 2021;193: E345-6.

2. Evenblij K, Pasman HRW, van Delden JJM, et al. Physicians' experiences with euthanasia: a crosssectional survey amongst a random sample of Dutch physicians to explore their concerns, feelings and pressure. BMC Fam Pract 2019;20:177.

3. Frei A, Schenker T, Finzen A, et al. The Werther effect and assisted suicide. Suicide Life Threat Behav 2003;33:192-200.

4. First annual report on medical assistance in dying in Canada. Ottawa: Health Canada; 2019. Available: https://www.canada.ca/content/ dam/hc-sc/documents/services/medical-assistance -dying-annual-report-2019/maid-annual-report -eng.pdf(accessed 2021 Mar. 1)

5. Annual report 2019. Netherlands: Regional Euthanasia Review Committee; 2019. Available: https:// english.euthanasiecommissie.nl/the-committees/ documents/publications/annual-reports/2002/ annual-reports/annual-reports (accessed 2021 Apr. 9). 
6. Canadian Mental Health Association on medical assistance in dying (MAID) [statement]. Toronto: Canadian Mental Health Association; 2021 Feb. 23. Available: https://cmha.ca/news/statement -on-medical-assistance-in-dying-maid (accessed 2021 Mar. 1).

7. Centre for Addiction and Mental Health (CAMH) policy advice on medical assistance in dying and mental illness. Toronto: Centre for Addiction and Mental Health; 2017.

8. Harris K, Bryden J. Proposed changes to assisted-dying law make death a viable option for people with disabilities, advocate fears. $C B C$ News 2020 Dec. 17. Available: https://www.cbc. ca/news/canada/british-columbia/maid-assisted -dying-bill-c7-bc-1.5845306 (accessed 2021 Mar. 1).

9. Bryden J. UN human rights experts alarmed by trend toward assisted dying for non-terminal conditions. Globe \& Mail [Toronto] 2020 Jan. 27. Available: https://www.theglobeandmail.com/ canada/article-un-human-rights-experts-alarmed -by-trend-toward-assisted-dying-for/ (accessed 2021 Mar. 1).
10. World Medical Association declaration on euthanasia and physician-assisted suicide. Adopted by the 70th WMA General Assembly, Tbilisi, Georgia, October 2019. Ferney-Voltaire (FR): World Medical Association; 2019. Available: https://www.wma. net/policies-post/declaration-on-euthanasia-and -physician-assisted-suicide/ (accessed 2021 Mar. 1).

11. British Medical Association position on physicianassisted dying. London (UK): British Medical Association; 2020 Sept. 28. Available: https://www. bma.org.uk/advice-and-support/ethics/end-of-life /the-bmas-position-on-physician-assisted-dying (accessed 2021 Mar. 1).

12. American Medical Association Code of Medical Ethics Opinion 5.8 (Euthanasia). Chicago: American Medical Association. Available: https://www. ama-assn.org/delivering-care/ethics/euthanasia (accessed 2021 Mar. 1)

13. American Medical Association Code of Medical Ethics Opinion 5.7 (PAS). Chicago: American Medical Association. Available: https://www.ama-assn.org/ delivering-care/ethics/physician-assisted-suicide (accessed 2021 Mar. 1).
14. American Psychiatric Association position statement on medical euthanasia. Washington (D.C.): American Psychiatric Association; 2016. Available: https://psychiatry.org/File\%20Library/About-APA/ Organization-Documents-Policies/Policies/Position -2016-Medical-Euthanasia.pdf (accessed 2021 Mar. 1).

15. Downar J, Fowler RA, Halko R, et al. Early experience with medical assistance in dying in Ontario, Canada: a cohort study. CMAJ 2020;192: E173-81.

\section{Competing interests: None declared.}

Content licence: This is an Open Access article distributed in accordance with the terms of the Creative Commons Attribution (CC BY-NC-ND 4.0) licence, which permits use, distribution and reproduction in any medium, provided that the original publication is properly cited, the use is noncommercial (i.e., research or educational use), and no modifications or adaptations are made. See: https://creativecommons.org/ licenses/by-nc-nd/4.0/ 